\title{
Wearable Flexible Lightweight Modular RFID Tag With Integrated Energy Harvester
}

\author{
Sam Lemey, Student Member, IEEE, Sam Agneessens, Patrick Van Torre, Kristof Baes, \\ Jan Vanfleteren, Member, IEEE, and Hendrik Rogier, Senior Member, IEEE
}

\begin{abstract}
A novel wearable radio frequency identification (RFID) tag with sensing, processing, and decision-taking capability is presented for operation in the 2.45-GHz RFID superhigh frequency (SHF) band. The tag is powered by an integrated light harvester, with a flexible battery serving as an energy buffer. The proposed active tag features excellent wearability, very high read range, enhanced functionality, flexible interfacing with diverse low-power sensors, and extended system autonomy through an innovative holistic microwave system design paradigm that takes antenna design into consideration from the very early stages. Specifically, a dedicated textile shorted circular patch antenna with monopolar radiation pattern is designed and optimized for highly efficient and stable operation within the frequency band of operation. In this process, the textile antenna's functionality is augmented by reusing its surface as an integration platform for light-energy-harvesting, sensing, processing, and transceiver hardware, without sacrificing antenna performance or the wearer's comfort. The RFID tag is validated by measuring its stand-alone and on-body characteristics in free-space conditions. Moreover, measurements in a real-world scenario demonstrate an indoor read range up to $23 \mathrm{~m}$ in nonlineof-sight indoor propagation conditions, enabling interrogation by a reader situated in another room. In addition, the RFID platform only consumes $168.3 \mu \mathrm{W}$, when sensing and processing are performed every $60 \mathrm{~s}$.
\end{abstract}

Index Terms-Battery-assisted, energy harvesting, Internet of Things (IoT), radio frequency identification (RFID), textile antenna, wearable.

\section{INTRODUCTION}

I $\mathrm{N}$ THE near future, it is expected that the Internetof-Things (IoT) paradigm will step out of its infancy [1], [2], fueled by the adaptation of a variety of

Manuscript received October 30, 2015; revised January 19, 2016 and May 20, 2016; accepted May 22, 2016. Date of publication June 13, 2016; date of current version July 7, 2016. This work was supported in part by the Inter-University Attraction Poles Program initiated by the Belgian Science Policy Office, in part by the iMinds Internet of Things Research Program, and in part by the Research Foundation Flanders (FWO-Vlaanderen).

S. Lemey is with the Department of Information Technology, Ghent University/iMinds, Ghent 9052, Belgium, and also with the Centre for Microsystems Technology, Department of Electronics and Information Systems, Ghent University/IMEC, Ghent 9052, Belgium (e-mail: sam.lemey@intec.ugent.be).

S. Agneessens is with the Department of Information Technology, Ghent University/iMinds, B-9052 Ghent, Belgium, and also with the Centre for Microsystems Technology, Department of Electronics and Information Systems, Ghent University/IMEC, Ghent 9052, Belgium. He is currently an FWO Postdoctoral Research Fellow with the Research Foundation Flanders, Brussel 1000, Belgium (e-mail: sam.agneessens@intec.ugent.be).).

P. Van Torre, K. Baes, and H. Rogier are with the Department of Information Technology, Ghent University/iMinds, Ghent 9052, Belgium (e-mail: patrick.vantorre@ugent.be; kristof.baes@ugent.be; hendrik.rogier@ugent.be).

J. Vanfleteren is with the Centre for Microsystems Technology, Department of Electronics and Information Systems, Ghent University/IMEC, Ghent 9052, Belgium (e-mail: jan.vanfleteren@elis.ugent.be).

Color versions of one or more of the figures in this paper are available online at http://ieeexplore.ieee.org.

Digital Object Identifier 10.1109/TMTT.2016.2573274 key-enabling technologies, such as radio frequency identification (RFID) [3], wireless sensor networks (WSNs) [4], [5], and wireless power transfer [6], [7]. The integration into the Internet of everyday objects, devices, and garments equipped with sensing, processing, and wireless communication capabilities will revolutionize many aspects of everyone's daily life [8]. Smart fabric interactive textile systems, in which unobtrusive integration of electronic components increases functionality of the garment [9], [10], play an important role within the vision of the IoT [8]. They will experience a significant growth in diverse application areas in the coming years [11], such as critical professional applications [12]-[14], health care [2], [15], [16], and sports [17]. Yet, to accelerate the pervasive deployment of the IoT, it is necessary to combine the potential of diverse, complementary, key-enabling technologies [18]-[22].

Several research efforts in the past few years have pushed passive RFID beyond simple barcode replacement to enhanced RFID tags. These combine the potential of WSN and RFID technologies to implement identification, sensing, arbitrary processing, data logging, and actuation functionality [22]-[26]. Integrating such an enhanced RFID/WSN tag within a garment will leverage pervasive quantification of the wearer's interaction with its environment by wirelessly communicating physical information about the wearer and his/her environment to the Internet via a question-and-reply protocol. This, however, introduces novel, stringent design requirements. First, the enhanced RFID tag functionality and larger operating range make system autonomy one of the major critical design constraints [21], [23]. Powering enhanced RFID tags exclusively by RF energy transmitted by RFID readers restricts data logging, sensing, and computational operations to the coverage range of the RFID reader [23], [27]. Reliability, functionality, and operation range may be increased [9], [23] by combining an antenna with high radiation efficiency and tailored radiation pattern [9], [28] with energy harvesters relying on ambient sources, such as vibration [29], kinetic [17], solar [23], [30], or RF energy [26]. Second, enhanced RFID tags for body-worn applications must be low-profile, lightweight, and mechanically flexible, allowing unobtrusive integration [28]. Moreover, the tag should maintain its performance in the proximity of the human body and under harsh operating conditions [31]. Finally, unwanted absorption of radiation by the human body should be minimized to prevent potential health threats [32].

In this paper, we introduce an innovative holistic RFID tag design paradigm for body-worn applications that takes antenna design into consideration from the very early stages. Adopting this paradigm leverages a new highly integrated, compact, 
low-profile RFID tag that combines excellent wearability with very high read range, enhanced functionality, and extended system autonomy. This active RFID tag is flexible, compact, low-profile, lightweight, and modular. It is equipped with sensing, processing, and decision-taking capability. The tag operates in the $2.45-\mathrm{GHz}$ RFID superhigh frequency (SHF) band and envisions communication with a smart floor/ ceiling [18], [33]. In this scenario, one or multiple RFID readers are integrated into the ceiling/floor of the building in which the wearer is walking around. Embedded software implements a novel protocol that logs sensor data to support the decision-taking process implemented on the node, in the meantime reducing energy consumption. An integrated lightenergy harvester further increases system autonomy, whereas an integrated flexible battery allows the tag to remain fully operative in the absence of light.

The current literature features a plethora of passive (battery-less) wearable, flexible RFID tags, based on novel implementation/manufacturing technologies, such as conductive thread embroidery on textile substrates [34], [35], substrate-integrated-waveguide (SIW) technology on textile [31], and inkjet-printing with conductive ink [17]. In contrast, the tag described here possesses more functionality and a much larger communication range compared with these passive RFIDs. The wearable RFID tag that is the most closely related to our proposed RFID platform in terms of functionality is the one proposed in [28]. However, as the tag in [28] is exclusively powered by the RFID reader, a read range of only $4 \mathrm{~m}$ is achieved, provided that the RFID reader transmits at a $30 \mathrm{dBm}$ power level. In contrast, our tag features an indoor read range up to $23 \mathrm{~m}$ when three brick walls are in between both the link ends and enables communication with a reader at an overhead floor, through a reinforced concrete floor. Therefore, our tag only consumes $168.3 \mu \mathrm{W}$ of power, when sensing and processing are performed every $60 \mathrm{~s}$, yielding a system autonomy of 138 days in the complete absence of light, provided that the battery was fully charged. Hence, our design significantly reduces the required amount of RFID readers to cover an entire building. Moreover, compared with the ad hoc antenna/harvester codesign strategy in [9], [36], and [37], our novel microwave system design paradigm also includes the integration of the transceiver, microcontroller, memory, and sensor hardware. This holistic approach leads to enhanced system autonomy, as the power consumption profile is now tailored to the power generation profile of the solar harvester by means of a dedicated algorithm. In addition, the tag now relies on a circular patch antenna that exploits shorted posts to tailor its radiation pattern for application in the smart floor/ceiling concept, instead of an SIW cavity-backed slot textile antenna that envisions body-to-body communication as in [9], [36], and [37].

The remainder of this paper is organized as follows. Section II describes the design and fabrication of our wearable, light-energy-harvesting-assisted RFID-based sensing, processing, and decision-taking platform. First, the design approach and system architecture are outlined. Next, we elaborate on the implementation of each subsystem (including the novel

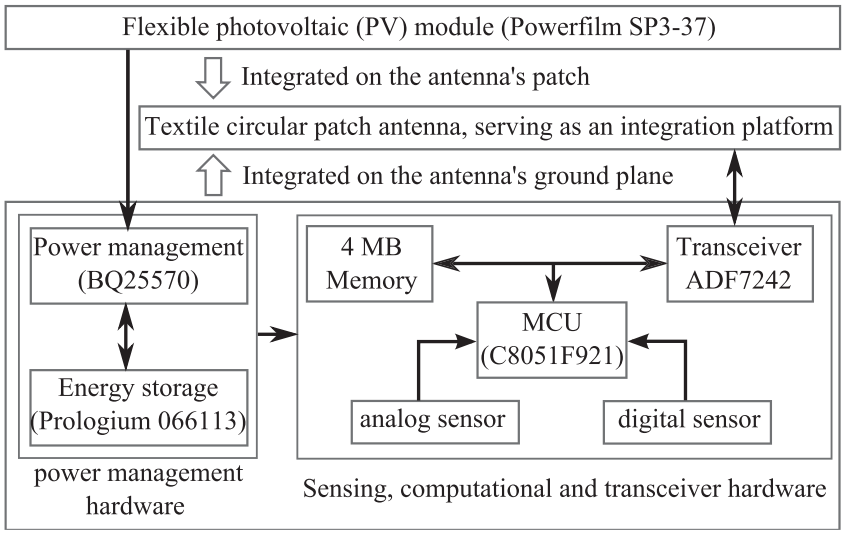

Fig. 1. Block diagram of the wearable, light-energy-harvesting RFID-based sensing platform.

textile antenna). Finally, the fabrication of the RFID tag is discussed. In Section III, experimental results as well as practical measurements are presented to validate simulation results and to demonstrate our platform's performance in terms of energy-harvesting potential, power consumption, communication distance, and antenna performance. The conclusion is drawn in Section IV.

\section{WeARABLE, Light-ENERGY-HARVESTING RFID-BASEd Sensing Platform Design}

\section{A. Design Considerations and Requirements}

The wearable RFID tag must not affect the comfort of the wearer under any circumstance. This does not only require a low-profile, flexible, and lightweight design, enabling unobtrusive integration, but also demands energy-efficient operation to avoid the discomfort of (frequent) battery recharging. Furthermore, a robust, stable, and long-range wireless communication link is desired to provide the wearer with the highest possible freedom of movement, without being out of read range. To meet these stringent requirements, a holistic microwave system design paradigm is adopted, in which antenna design is taken into consideration from the very early stages. Indeed, as the antenna performs a vital task within the wireless tag, an inappropriate design of this component will inadvertently lead to short communication range, poor energy efficiency (quickly draining batteries), and discomfort to the user [28].

\section{B. System Architecture}

Fig. 1 shows a block diagram of the light-energy-harvesting RFID-based sensing platform that fulfills the requirements stated in Section II-A. Fig. 1 also shows our design approach. A circular patch antenna, designed to operate with maximum total efficiency in the $2.45-\mathrm{GHz}$ RFID SHF band, serves as an integration platform for a flexible photovoltaic (PV) module, with the power management system (including energy storage) and sensing, processing, and transceiver hardware integrated on its feed plane. This topology, implemented in appropriate materials, yields a wearable, highly integrated, and 
low-profile antenna, realizing a robust, efficient, and longrange wireless communication link. The implementation of each block, as well as the component selection, is discussed into more detail in Sections II-C-II-E. The fabrication of the entire system is described in Section II-F.

\section{Textile Antenna Design and Fabrication}

A mobile user prefers a compact antenna for inconspicuous integration, whereas an antenna engineer will opt for larger dimensions (in the order of half a wavelength) to obtain better overall performance. A good design must reconcile these two conflicting demands to achieve optimal system performance with manageable dimensions. In addition, as our design is envisioned for communication with a smart floor/ceiling, in which an interrogator is located at either low or high elevation angles, an antenna with a radiation pattern where these angles of arrival are well received is required. This rules out conventional patch antennas, a popular choice for body-worn applications as their main direction of radiation is orthogonal to the user and not directed toward the floor or ceiling. Yet, high body-antenna isolation should be pursued to prevent antenna detuning caused by the presence of the human body. Finally, the adopted antenna topology and implementation technology must enable straightforward integration of carefully selected active low-power electronics (transceiver, microcontroller, and so on) that implement the desired functionality (such as logging sensor data, processing, and decision-taking), and appropriate energy harvesters, which further increase system autonomy, without performance degradation or discomfort for the wearer. From the RFID designer's point of view, a large antenna can provide interesting possibilities, as its area may be reused to integrate the complete system [38], [39].

To this end, a low-profile topology implemented in low-cost, lightweight, and flexible textile materials is selected, based on [40]. The topology consists of a circular patch with four shorting vias, connecting the patch to the ground plane. The antenna is fed by a probe in the center. Fig. 2 shows the tag's geometry. The shorting posts enable the excitation of the $\mathrm{TM}_{22}$ mode, which gives the antenna a monopolelike radiation pattern, allowing reliable communication between a bodyworn node and an interrogator located in a smart floor/ceiling.

The most important parameters for antenna optimization are the position of the shorting posts $\left(R_{S}\right)$ and the radius of the patch $\left(R_{p}\right)$. The size of the patch has a significant influence on the resonance frequency, while the position of the shorting posts can be adjusted to improve the matching to $50 \Omega$ (Fig. 3). Furthermore, Fig. 4 shows the simulated radiation pattern at $2.45 \mathrm{GHz}$, when the patch is deployed in the center of a ground plane of size $W_{\mathrm{GND}}=L_{\mathrm{GND}}=113 \mathrm{~mm}$, and for the ground plane dimensions shown in Fig. 2. Observe that by shrinking the width of the ground plane, while keeping the length sufficiently large, the antenna can be made more compact, without reducing sensitivity in the direction of the floor and ceiling [i.e., in the $y z$ plane $\left(\phi=90^{\circ}\right)$ ].

System integration can be improved by carefully selecting the fabrication materials. A low-cost protective textile foam

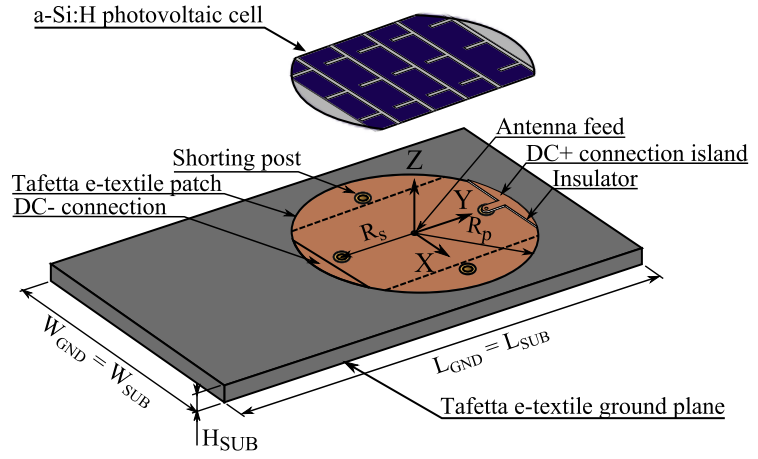

(a)

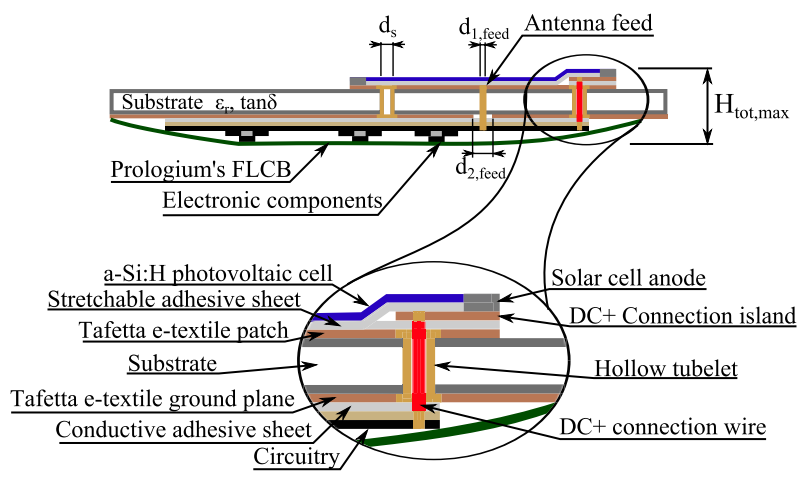

(b)

Fig. 2. Wearable, light-energy-harvesting RFID-based sensing platform, consisting of a circular patch antenna with four shorting tubelet posts, on which a flexible a-Si:H PV module is integrated onto its antenna patch and power management, sensing, processing, and transceiver hardware are integrated onto its ground plane $\left(R_{s}=19.75 \mathrm{~mm}, d_{s}=2 \mathrm{~mm}, R_{p}=27.5 \mathrm{~mm}, d_{1 \text {, feed }}=\right.$ $1.3 \mathrm{~mm}, d_{2 \text {,feed }}=4.6 \mathrm{~mm}, H_{\mathrm{SUB}}=3.94 \mathrm{~mm}, W_{\mathrm{GND}}=W_{\mathrm{SUB}}=66 \mathrm{~mm}$, $L_{\mathrm{GND}}=L_{\mathrm{SUB}}=113 \mathrm{~mm}$, and $H_{\mathrm{tot}, \max }=6.6 \mathrm{~mm}$ ). (a) Top 3-D view. (b) Cross-sectional view of the enlarged inset.

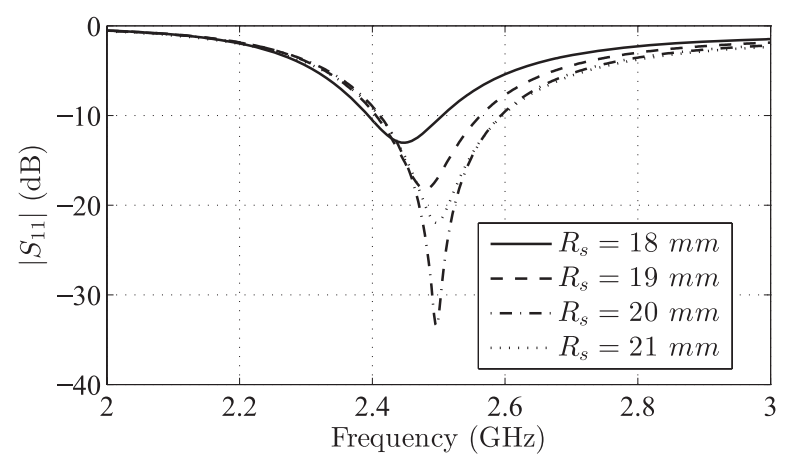

Fig. 3. Effect of the position of the shorting posts $\left(R_{S}\right)$ on the antenna's reflection coefficient.

$\left(\epsilon_{r}=1.42\right.$ and $\tan _{d}=0.016$ at $2.45 \mathrm{GHz}, H_{\mathrm{SUB}}=$ $3.94 \mathrm{~mm} \mathrm{[41])} \mathrm{is} \mathrm{used} \mathrm{as} \mathrm{an} \mathrm{antenna} \mathrm{substrate} \mathrm{to} \mathrm{achieve}$ sufficient bandwidth, while guaranteeing a low-profile, flexible, and lightweight antenna design. The conductive patch and ground plane are fabricated from conductive textile materials (surface resistivity $R_{s}=0.18 \Omega / \mathrm{sq}$ [41]), which are laminated to the dielectric antenna substrate by means of a thermally activated glue. Hollow, brass eyelets realize the shorting 


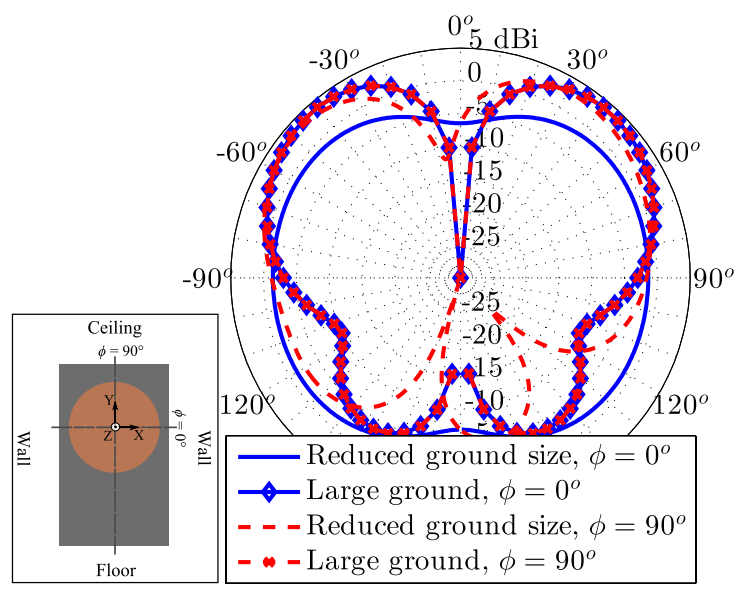

Fig. 4. Effect of ground plane size on the antenna's radiation pattern.

connections between the ground plane and the antenna patch. They are manually fixed with a hand press. Antenna optimization is performed by full-wave electromagnetic simulations in CST Microwave Studio. The final dimensions can be found in Fig. 2. The simulated performance of the antenna, in terms of impedance matching and radiation pattern, is shown in Figs. 7 and 8, respectively.

As radiation originates only from the radiating edge of the patch, a low profile object can be placed on the patch without altering the antenna's operation. Furthermore, the eyelets applied to make the shorting connection between the patch and the ground plane are hollow, which makes it possible to rout wires from the front side of the tag (top of the antenna patch) to the backside (behind the ground plane). Hence, the topology allows for easy integration of a PV module on top of the patch. It can be easily connected to a power management circuit, placed underneath the antenna.

The directional nature of the radiation pattern is another asset of this topology. The ground plane directs all radiation toward one hemisphere and shields the other side from the radiating parts. Thereby, it enables the placement of electronics behind the ground plane, where they are not exposed to the radiated electromagnetic fields of the antenna. In addition, the antenna is not influenced by the presence of the electronics or a human body in its near field, resulting in robust and reliable performance.

\section{Sensing, Computational, and Transceiver Hardware}

As shown in Fig. 1, the advanced low-power C8051F921 microcontroller by Silicon Laboratories is selected to form the heart of the sensing, processing, and transceiver hardware. The lowest-power sleep mode is employed in this design. The microcontroller contains a SmaRTClock, which is a real-time clock performing cyclic wake-up from sleep mode. According to the specifications, the microcontroller chip consumes $<1 \mu \mathrm{A}$ of supply current in sleep mode, with the SmaRTClock running. Different sensors may be connected to this microcontroller through analog as well as digital inputs. The device is programmed in the $\mathrm{C}$ language and contains all the software to control the wireless transceiver together with the sensors. Moreover, it implements the node's low-power algorithm.

An Analog Devices ADF7242 transceiver is applied for communication in IEEE802.15.4 mode [42]. The wireless transceiver exchanges data with the microcontroller over a serial peripheral interface (SPI). Also the ADF7242 can be configured in a low-power sleep mode, reducing its supply current to $<1 \mu \mathrm{A}$, provided that all oscillators are shut down. The ADF7242 transceiver's RF output port, characterized by a complex chip impedance $Z_{\text {chip }}=(74.3-10.7 j) \Omega$ at $2.45 \mathrm{GHz}$, is conjugate matched to the $50-\Omega$ antenna feed via a Johansson Technology 2450BM14E0007 balun.

A 1-MB Microchip 25AA1024 serial EEPROM memory is also included for nonvolatile data storage. Sensor measurements can be logged here and a history of measurements can be requested at the time of interrogation. The EEPROM memory can also be put in a deep power-down mode, such that it consumes a little over $1 \mu \mathrm{A}$ of supply current when it is not operational.

Employing a state-of-the-art transceiver component allows reliable communication over a long range [43]. The microcontroller provides plenty of sensor connectivity and can be conveniently configured to process sensor data in real time. Digital sensors can be connected via an SPI or $\mathrm{I}^{2} \mathrm{C}$ bus. Analog sensors can also be directly connected, as the microcontroller contains a 10-bit analog to digital converter. Local processing of the sensor data for unit conversions, filtering, or statistical processing is possible, providing a reduction in the amount of data to be transmitted. A large nonvolatile storage capacity is available for measurement data.

Since all selected components provide a low-power mode, a very low average supply current is achieved, enabling extended battery-supported operation.

\section{E. Energy Harvesting and Power Management Hardware}

Powerfilm's ultrathin $(200 \mu \mathrm{m})$ and ultraflexible SP3-37 hydrogenated amorphous silicon (a-Si:H) PV ambient light-energy-harvesting transducer [23], positioned on top of the antenna, is connected to the power management subsystem, located on the node's feed plane. This particular PV module is selected because of four multidisciplinary reasons. First, the SP3-37 harvester exhibits a broad spectral response, not only enabling energy harvesting from solar light but also from the most frequently available light sources in an indoor environment [9], [23]. More specifically, the SP3-37 PV module is characterized by a maximum output voltage of $3 \mathrm{~V}$ at $22 \mathrm{~mA}$ under full sunlight (107527 lx) and a maximum output voltage of $2.5 \mathrm{~V}$ at $100 \mu \mathrm{A}$ under typical office lighting (330 lx) [23]. Second, its flexible and ultrathin structure permits a conformal and low-profile integration [44]. Third, the SP3-37 is manufactured through a low-cost roll-to-roll printing process, making it compatible with current RFID production processes [23]. Finally, the harvester's relatively small size, and the ease of patterning the solar cell's surface to fit the antenna patch contours facilitate the integration procedure. 


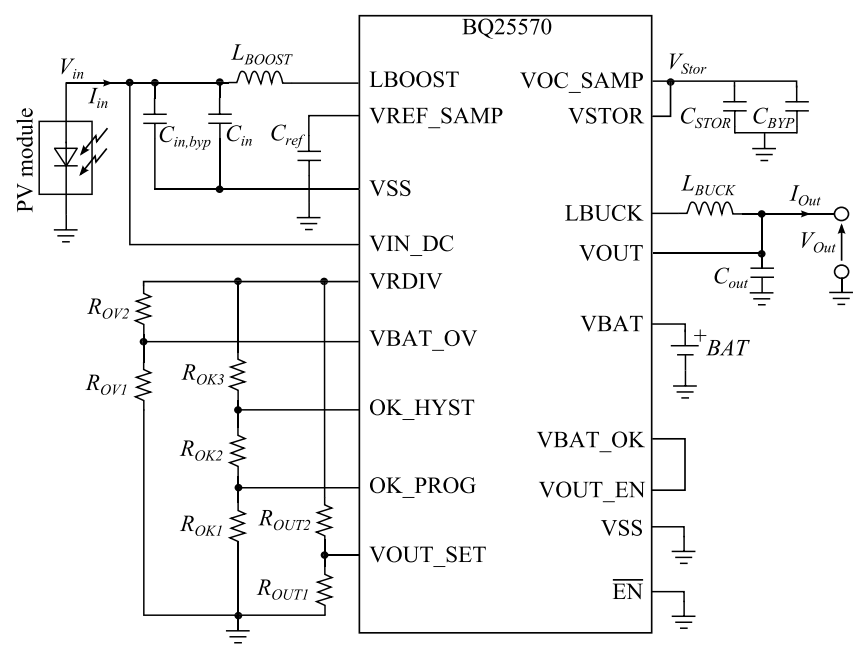

Fig. 5. Circuit schematic of the energy harvesting and power management hardware $\left(C_{\text {in,byp }}=100 \mathrm{nF}, C_{\text {in }}=4.7 \mu \mathrm{F}, C_{\text {ref }}=10 \mathrm{nF}, C_{\mathrm{STOR}}=4.7 \mu \mathrm{F}\right.$, $C_{\mathrm{BYP}}=100 \mathrm{nF}, C_{\mathrm{out}}=44 \mu \mathrm{F}, L_{\mathrm{BOOST}}=22 \mu \mathrm{H}, L_{\mathrm{BUCK}}=10 \mu \mathrm{H}$ $R_{\mathrm{OV} 1}=5.62 \mathrm{M} \Omega, R_{\mathrm{OV} 2}=7.32 \mathrm{M} \Omega, R_{\mathrm{OK} 1}=3.83 \mathrm{M} \Omega, R_{\mathrm{OK} 2}=7.5 \mathrm{M} \Omega$ $R_{\mathrm{OK} 3}=680 \mathrm{k} \Omega, R_{\mathrm{OUT} 1}=4.64 \mathrm{M} \Omega$, and $R_{\mathrm{OUT} 2}=8.25 \mathrm{M} \Omega$ ).

For a given PV module at a specific temperature, the instantaneous generated power depends on the spectral composition, incident angle, and the intensity of the light impinging on the PV module [9]. This requires a power management system that converts the highly fluctuating, and often small, levels of harvested light energy into a form useful for adequately powering the node. To this end, the Texas Instruments bq25570, an integrated energy-harvesting nanopower management system (Fig. 5), is applied. This integrated circuit (IC) implements two highly efficient conversion stages. The first stage encompasses a pulse-frequency modulated (PFM) boost converter charger, with maximum-power-point-tracking (MPPT) capability, to efficiently store the energy generated by the energy-harvesting transducer in a suitable energy storage device. During the charging process, the energy storage component is protected from overcharging by disabling the boost converter once the voltage at VBAT (Fig. 5) exceeds $4.18 \mathrm{~V}$, set by selecting the proper values for $R_{\mathrm{OV} 1}$ and $R_{\mathrm{OV} 2}$. As the PV module's maximum output power fluctuates in ambient light conditions, the fractional open circuit algorithm is adopted to optimize power transfer from the PV unit to the energy storage device. This means that the bq25570 periodically (every $16 \mathrm{~s}$ ) samples the open circuit input voltage of the PV module, by disabling the boost converter for $256 \mathrm{~ms}$, and determines the MPP during that particular time interval. In this paper, the boost converter is configured to subsequently load the light-energy-harvesting transducer until its voltage drops to $80 \%$ of the sampled open circuit voltage. This periodic update continually maximizes power delivery in real time, based on the harvesting conditions. The second conversion stage consists of a highly efficient, nanopower PFM buck converter, providing a regulated power supply to the sensing, processing, and transceiver hardware. In this paper, the buck converter/output regulator is set by means of $R_{\text {OUT1 }}$ and $R_{\text {OUT2 }}$ to provide a regulated output voltage of $3.36 \mathrm{~V}$. Yet, to prevent overdischarging, the output voltage is disabled when VBAT (Fig. 5) drops below $3.60 \mathrm{~V}$. It is only turned back ON after the VBAT voltage exceeds $3.82 \mathrm{~V}$. Both the voltage levels are set by means of the voltage divider formed by $R_{\mathrm{OK} 1}, R_{\mathrm{OK} 2}$, and $R_{\mathrm{OK} 3}$. The other passive components are dimensioned to obtain the highest possible efficiency for both the conversion stages of the IC.

The availability of ambient light will often be sporadic or time-varying, thereby necessitating some type of energy storage element. Such a storage element will not only ensure that the required power is available when needed by the node but also will handle peak currents that cannot directly be delivered by the PV module. The single cell version of Prologium's 066113 Flexible Printed Circuit Lithium Ceramic Battery (FLCB) is selected as the node's energy storage element. This FLCB cell is only $380 \mu \mathrm{m}$ thick and covers an area of $113 \mathrm{~mm} \times 66 \mathrm{~mm}$. It exhibits a nominal capacity of $170 \mathrm{mAh}$ and allows a maximum discharge current of $120 \mathrm{~mA}$. The FLCB technology is selected because it exhibits favorable electrical properties, such as high energy density and good pulse discharge. Moreover, it can be manufactured through a roll-to-roll printing production process, reducing manufacturing cost. Furthermore, its ability to dynamically bend and/or twist, without reducing neither cycle life nor electrical performance, in combination with its ultrathin $(380 \mu \mathrm{m})$ profile, facilitates integration on the textile antenna without significantly increasing its overall thickness or significantly reducing the overall conformality. In addition, the FLCB technology does not exhibit leakage, catch fire, or explode after physical abuse (nail penetration, excessive vibrations, drop test, and so on), after thermal test conditions up to $250{ }^{\circ} \mathrm{C}$ or after electrical abuse (overcharging, reverse charging, and short circuiting), demonstrating its ability to be safely worn on the human body, even in harsh environments.

\section{F. Integration Procedure}

Once the textile antenna is fabricated according to Section II-C, the flexible PV module is glued on top of the antenna patch by means of stretchable, nonconductive adhesive sheets, as shown in Fig. 2. To maintain the antenna's excellent performance after solar cell integration, the PV module is patterned to fit the antenna patch contours and placed in such a way that the radiating edge remains uncovered. Furthermore, the PV module is modified to facilitate the connection of its dc-terminals from its bottom side. The negative dc terminal of the PV module is directly connected to the antenna patch, acting as a dc ground. The positive dc terminal is connected to a dc connection island, fabricated out of pure copper-coated e-textile and isolated from the antenna patch by means of a nonconductive adhesive sheet, as shown in the enlarged inset shown in Fig. 2(b). The dc connection island is connected to the power management system via a wire routed through one of the hollow tubelets. These measures not only reduce the number and length of interconnecting wires but also prevent that interconnections influence the radiation characteristics of the antenna, resulting in a more robust design and improved comfort for the user.

Next, we integrate the processing, power management and transceiver hardware. These components are implemented on 


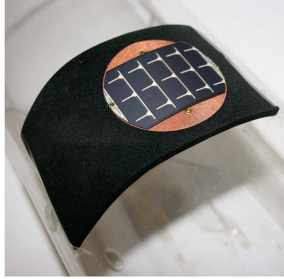

(a)

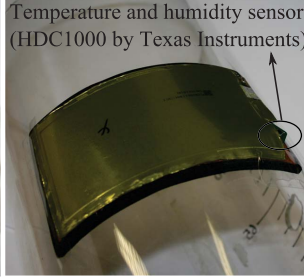

(b)

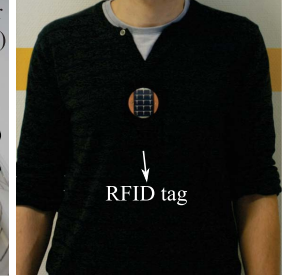

(c)
Fig. 6. Prototype of the wearable, RFID tag with integrated light harvester (top) and flexible battery (bottom). (a) Top view: bending diameter $=15 \mathrm{~cm}$. (b) Bottom view: bending diameter $=15 \mathrm{~cm}$. (c) On-body deployment.

a compact, low-profile, polyimide flexible circuit board (FCB), as in [9], [41], and [43]. To maintain flexibility, small electronic components were selected and distributed over a sufficiently large area to allow for small bending radii. Furthermore, special care was taken to avoid vias, whenever possible, and to position components on only one side of the FCB. This leads to a circuit bottom layer that almost entirely consists of a copper ground plane. The FCB is then integrated onto the antenna's feed plane by means of a conductive adhesive sheet, bonding the antenna ground plane with the circuit ground plane, as shown in Fig. 2(b). This approach allows using the antenna as a common dc ground and yields excellent shielding between the antenna patch and the active circuitry, owing to the ground plane.

As the antenna's ground plane is slightly larger than Prologium's 066113 FLCB, integration of the FLCB at the antenna's backside, as shown in Fig. 2(b), will not affect the antenna's radiation performance. Moreover, its ultrathin profile only adds $380 \mu \mathrm{m}$ to the total thickness of the entire stack. The FLCB's cathode is directly connected to the antenna's ground plane, acting as a common dc ground, whereas its anode is connected to the power management subcircuit. A prototype of our wearable, light-energy-harvesting-assisted RFID-based sensing platform is shown in Fig. 6. The figure shows that we have connected an HDC1000 low power humidity and temperature sensor by Texas Instruments, implemented on an FR4 printed circuit board, via the $\mathrm{I}^{2} \mathrm{C}$ bus, as a proof of principle. In a future design, this sensor may be directly implemented on the FCB as well. The sensor was selected as temperature and humidity are key parameters in diverse medical environments, for instance to assess the integrity of drugs or to detect the arise of an epidemic source producing fever rush [2].

\section{MEASUREMENT RESUlts}

\section{A. Textile Antenna Performance}

To validate the antenna performance and the integration procedure, the antenna's figures of merit are measured under different operating conditions. First, the antenna performance is analyzed before and after the integration of the additional light-energy-harvesting, power management, sensing, processing, and transceiver hardware. Afterward, the antenna performance is measured when deployed on the human body.

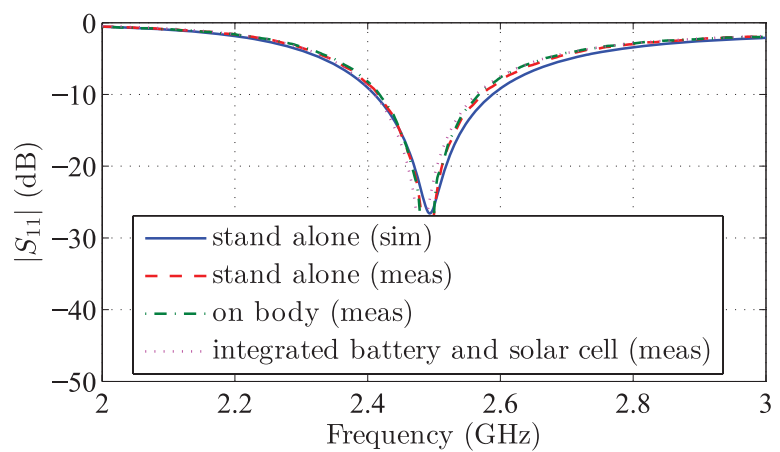

Fig. 7. Reflection coefficients of the textile antenna, under free-space conditions, to validate the integration procedure and its on-body performance.

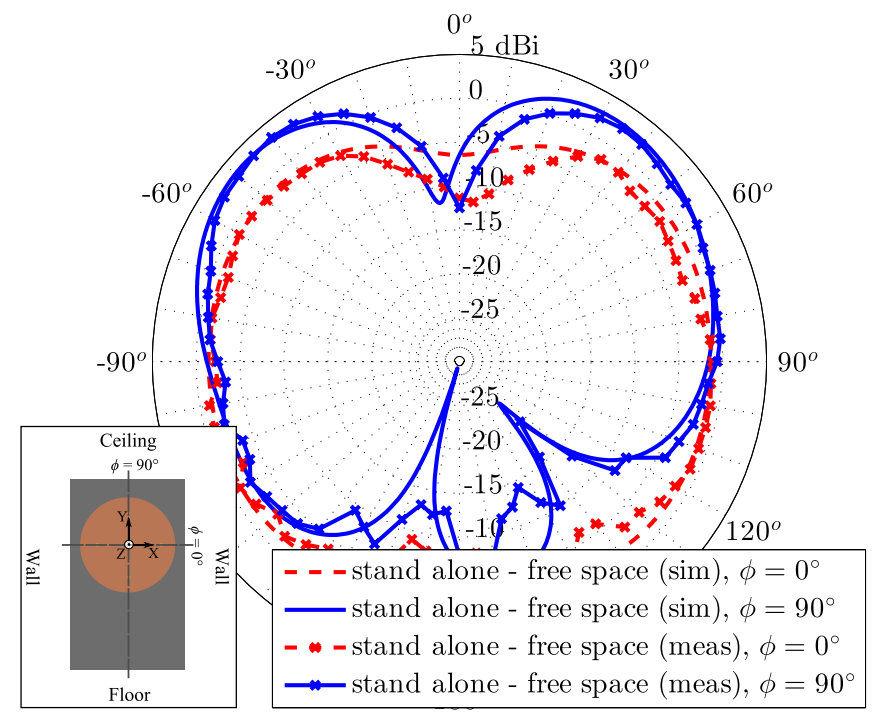

Fig. 8. Simulated and measured radiation pattern of the stand-alone textile antenna at $2.45 \mathrm{GHz}$.

All measurements are conducted in an anechoic room, where external interferers are absent.

Impedance matching to a $50-\Omega$ source is validated by means of an Agilent PNA-X vector network analyzer. The antenna should have good impedance matching $\left(\left|S_{11}\right|<-10 \mathrm{~dB}\right)$ around the $2.45 \mathrm{GHz}$ center frequency, irrespective of the operating condition. Comparison of the measured reflection coefficients in Fig. 7 demonstrates stable results for all different conditions with an impedance bandwidth of more than $150 \mathrm{MHz}$ or $6.1 \%$. In addition,good agreement with the simulated curve is observed.

The gain pattern and how it is affected by the different operating conditions are also evaluated. Fig. 8 shows the simulated and measured radiation patterns for the $\phi=0^{\circ}$ and $\phi=90^{\circ}$ cross-sections. It is seen that the antenna exhibits a monopolar radiation pattern with most of the radiation directed toward the ceiling and the floor $\left(\phi=90^{\circ}\right)$. In contrast, due to the smaller ground plane size, there is less radiation toward the walls $\left(\phi=0^{\circ}\right)$, with a gain difference of $\sim 4 \mathrm{~dB}$. In the stand-alone scenario, a measured maximum gain of $3.3 \mathrm{dBi}$ at the direction $(\theta, \phi)=\left(-40^{\circ}, 90^{\circ}\right)$, a $3-\mathrm{dB}$ beamwidth of more than $50^{\circ}$ and a total efficiency of $66 \%$ is obtained. 


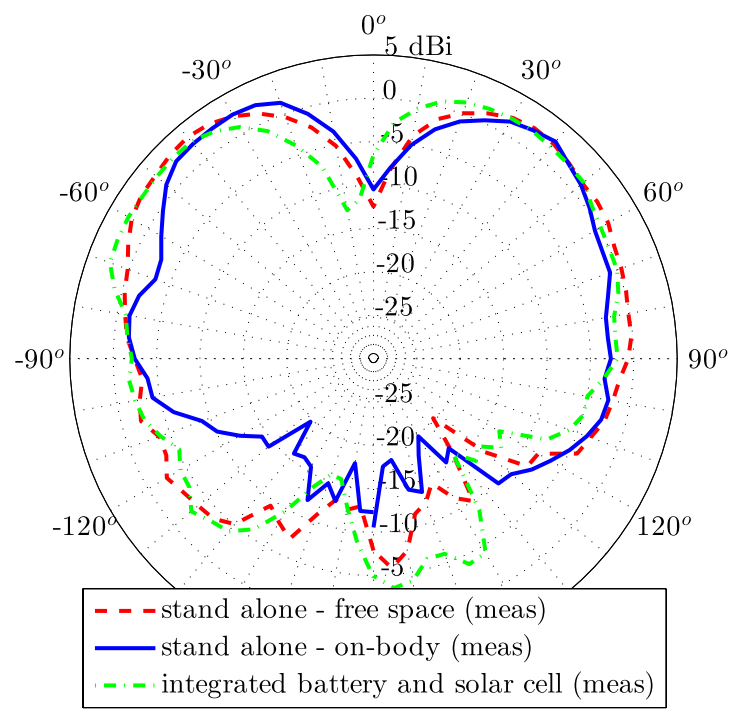

Fig. 9. Measured radiation pattern of the textile antenna at $2.45 \mathrm{GHz}$, under free-space conditions, to validate the integration procedure and its on-body performance.

Fig. 9 shows the radiation pattern at $2.45 \mathrm{GHz}$ before and after integration of the light-energy-harvesting, power management, sensing, processing and transceiver hardware. When integrating the solar cell on top and the flexible battery behind the antenna, the radiation pattern remains stable, with a maximal measured gain of $2.7 \mathrm{dBi}$ and an efficiency of $65 \%$. It is noted that the integrated radiation pattern is slightly rotated with respect to the stand-alone and on-body cases, which is caused by a small alignment error during measurement. Despite this, it can clearly be seen that the shape and absolute values of the patterns remain very stable. The design also performs well in the on-body scenario (Fig. 9). The presence of the human body only has a slight influence on the pattern: the direction of maximal gain corresponds to $(\theta, \phi)=\left(-20^{\circ}, 90^{\circ}\right)$ with a value of $2.5 \mathrm{dBi}$ and more than $50^{\circ} 3-\mathrm{dB}$ beamwidth.

These measurements validate that the antenna remains very stable under the different operating conditions, both in terms of impedance matching and radiation performance.

\section{B. Light-Energy-Harvesting Potential}

A Keithley 236 source meter and a solar simulator, with a standardized illumination level of $100 \mathrm{~mW} / \mathrm{cm}^{2}$, were used to measure the dc $P-V$ characteristic of the SP3-37 PV module before and after patterning its surface to fit the antenna patch contour. Fig. 10 shows both curves and shows that the maximum power generated by the PV module reduces from 56.9 down to $50.1 \mathrm{~mW}$ by modifying its surface. This decrease can be attributed to a smaller effective light aperture and shunt resistance after modification.

The boost converter/charger stage of the power management hardware is designed to minimize the required input voltage and power. This enables ambient light-energy harvesting in near minimum lighting requirements. For indoor environments, the Occupational Safety and Health Administration

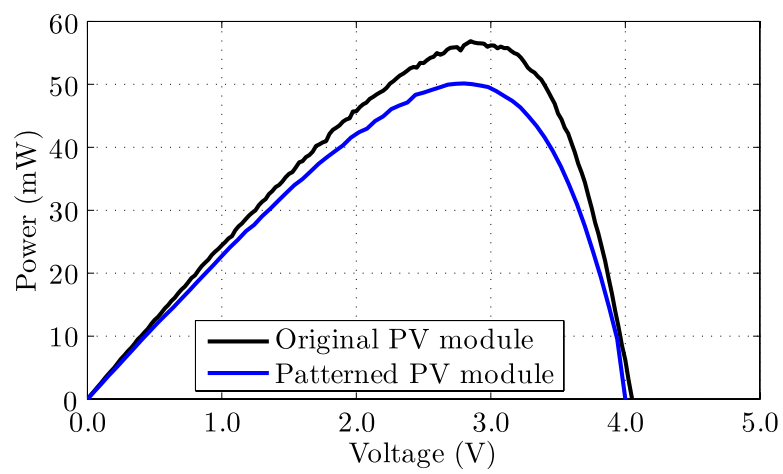

Fig. 10. DC $P-V$ characteristic of the flexible solar cell, before and after patterning.

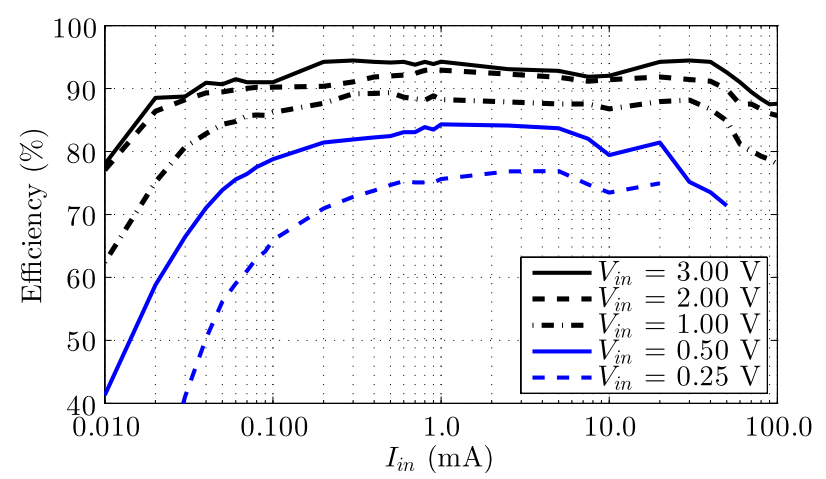

Fig. 11. Boost charger efficiency as a function of input current $\left(I_{\text {in }}\right)$ for different input voltage ( $V_{\text {in }}$ ) levels and $V_{\text {Stor }}$ fixed to $3.9 \mathrm{~V}$ (Fig. 5).

specificies these conditions as $150 \mathrm{~lx}$ for a warehouse, $330 \mathrm{~lx}$ for an office, and $650 \mathrm{~lx}$ for a supermarket environment [23]. Measurements have demonstrated that the boost charger allows harvesting ambient light energy as long as the PV module is capable of generating a voltage and power level exceeding $110 \mathrm{mV}$ and $6 \mu \mathrm{W}$, respectively. This is the case when the patterned PV harvester is illuminated by white LED light at an illumination level higher than $330 \mathrm{~lx}$, and when illuminated by fluorescent light at an illumination level exceeding $150 \mathrm{~lx}$.

Next, two Keithley 2400 source meters and a Fluke 45 multimeter were applied to accurately characterize the boost charger and buck regulator efficiency. The boost charger efficiency is shown in Fig. 11, as a function of input current $\left(I_{\text {in }}\right)$, for different input voltage levels $\left(V_{\text {in }}\right)$ and $V_{\text {Stor }}$ fixed to $3.9 \mathrm{~V}$ (Fig. 5). Fig. 11 demonstrates that the boost charger stage operates more efficiently for larger values of the input voltage. A maximum achievable efficiency of over $90 \%$ can be observed in Fig. 11. Yet, even for $V_{\text {in }}=0.25 \mathrm{~V}$, the boost charger efficiency exceeds $70 \%$ for input currents larger than $200 \mu \mathrm{A}$.

Fig. 12 shows the buck converter/regulator efficiency, as a function of output current $\left(I_{\text {Out }}\right)$, for a regulated output voltage ( $\left.V_{\text {Out }}\right)$ of $3.36 \mathrm{~V}$ and $V_{\text {stor }}$ fixed to $3.9 \mathrm{~V}$ (Fig. 5). Fig. 12 proves that the buck converter regulator is able to guarantee an efficiency higher than $75 \%$ from an output current as low as $3.8 \mu \mathrm{A}$ to output currents exceeding $100 \mathrm{~mA}$. 


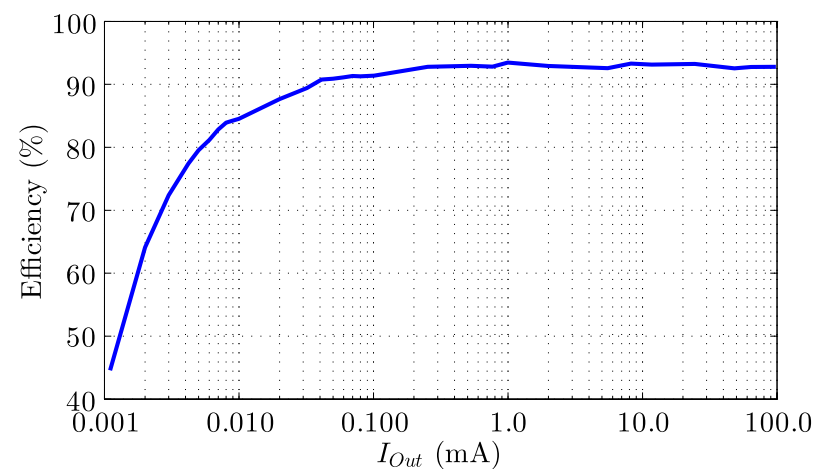

Fig. 12. Buck regulator efficiency as a function of output current ( $\left.I_{\text {Out }}\right)$ for $V_{\text {Out }}$ regulated to $3.36 \mathrm{~V}$ and $V_{\text {stor }}$ fixed to $3.9 \mathrm{~V}$ (Fig. 5).

TABLE I

RECEIVEd Signal LEVEl For DifFERENT REAding SCENARios

\begin{tabular}{cc}
\hline Transmitter location & Received signal level $(\mathrm{dBm})$ \\
LoS $1 \mathrm{~m}$ & -39.4 \\
LoS $2 \mathrm{~m}$ & -41.2 \\
NLoS $5 \mathrm{~m}$ & -55.5 \\
NLoS $13 \mathrm{~m}$ & -70.4 \\
NLoS $23 \mathrm{~m}$ & -85.8 \\
NLoS 1 floor up, overhead & -64.2 \\
NLoS 1 floor up, $10 \mathrm{~m}$ off & -75.5 \\
\hline
\end{tabular}

\section{Read Range}

The read range of the RFID sensor system is large enough to enable reading from another room, or another floor in a building. The indoor range has been tested to be up to $23 \mathrm{~m}$ in nonline-of-sight (NLoS) indoor propagation conditions. Interrogation of nodes, or garments with integrated nodes, which are stored in a standard metal office closet is also possible. A standard closet does not provide enough attenuation to block the communication between the RFID node and the interrogator.

The measurement of the received signal strength $(\mathrm{dBm})$ is performed for the ADF7242 transceiver chip deployed on the RFID node as well as on the interrogator. According to specifications, the minimum required received signal strength to successfully decode IEEE802.15.4 packets is $-95 \mathrm{dBm}$. Table I lists a number of measured received signal levels in practical conditions. Fig. 13 shows the measurement setup and a floor plan of the real-life environment, with all practical test locations annotated. LoS measurements are performed within the same room, whereas NLoS conditions imply communication between rooms in the same building. The building is composed of a steel structure with reinforced concrete floors and solid brick walls. At 13 and $23 \mathrm{~m}$, two and three brick walls are in between both link ends, respectively. Communication from the overhead floor is also included, through the reinforced concrete floor. Two measurements of this type are included, one with the RFID node directly overhead on the upper floor, and one with the node $10 \mathrm{~m}$ further away from this position.

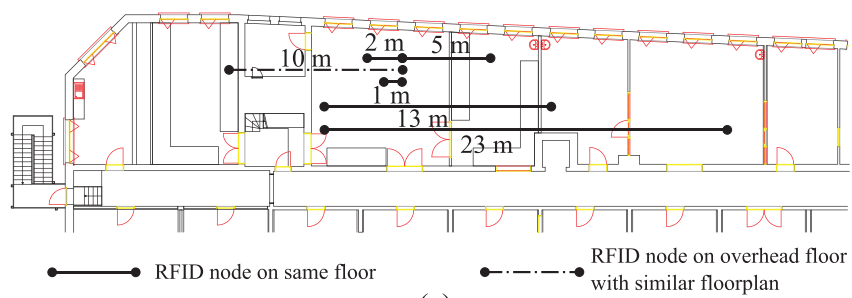

(a)

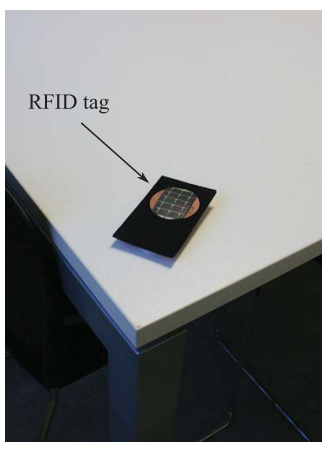

(b)

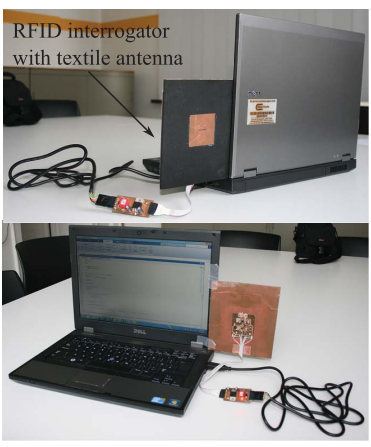

(c)
Fig. 13. Read range measurement setup. (a) Floorplan with all reading scenarios annotated (Table I). (b) RFID tag. (c) RFID interrogator with textile antenna [43].

\section{Current Consumption Profile}

The average current consumption of the RFID node is controlled by adjusting the amount of time the system is in sleep mode, as in this state, a current of only $8 \mu \mathrm{A}$ is consumed. Compared with the leakage current of the battery, which is $\sim 40 \mu \mathrm{A}$, this is a very low power consumption. However, when the node switches to its active states, the current consumption increases up to $35 \mathrm{~mA}$, although this maximum current is only drawn during a period of $5 \mathrm{~ms}$ each time the node wakes up.

The current for different operation modes was measured by a Tektronix MSO2014B mixed signal oscilloscope, with a $1 \Omega$ resistor in series with the power supply ground. In Fig. 14, the current is displayed during receive (RX) mode. During the power-up event, the microcontroller first awakens from sleep mode, causing a current of $5 \mathrm{~mA}$, then the ADF7242 transceiver chip is also awoken from its sleep mode. Some initialization time is necessary for the transceiver before actual packets can be received. As soon as the transceiver operates in RX mode, a current of $35 \mathrm{~mA}$ is consumed. During this mode, the transceiver keeps waiting for a valid packet. However, a time-out is implemented in the software to allow the system to return to sleep mode after a while if no packet is received.

The measured average current consumption during the active period $T_{\text {Active }}=8 \mathrm{~ms}$ is $I_{\text {Active }}=22.45 \mathrm{~mA}$, yielding for an average current consumption of the system for a wake-up period $T_{\text {Sleep }}$

$$
I_{\text {Avg }}=\frac{T_{\text {Active }} \cdot I_{\text {Active }}+T_{\text {Sleep }} \cdot I_{\text {Sleep }}}{T_{\text {Sleep }}+T_{\text {Active }}}
$$

with $I_{\text {Sleep }}=8 \mu \mathrm{A}$. 
TABLE II

Average CURRENT CONSUMPTION AND SYSTEM AUtONOMY FOR DifFERENT SLEEP PERIOdS AND FOR TWO BATTERY TYPES

\begin{tabular}{cccc}
\hline $\begin{array}{c}\text { Sleep Time } \\
(s)\end{array}$ & $\begin{array}{c}\text { Average Supply Current } \\
(\mu A)\end{array}$ & \multicolumn{2}{c}{$\begin{array}{c}\text { System autonomy } \\
\text { (days) }\end{array}$} \\
& & FLCB & Coin cell \\
1 & 186 & 31 & 25 \\
2 & 97 & 51 & 46 \\
5 & 44 & 84 & 90 \\
10 & 26 & 107 & 134 \\
60 & 11 & 138 & 226 \\
\hline
\end{tabular}

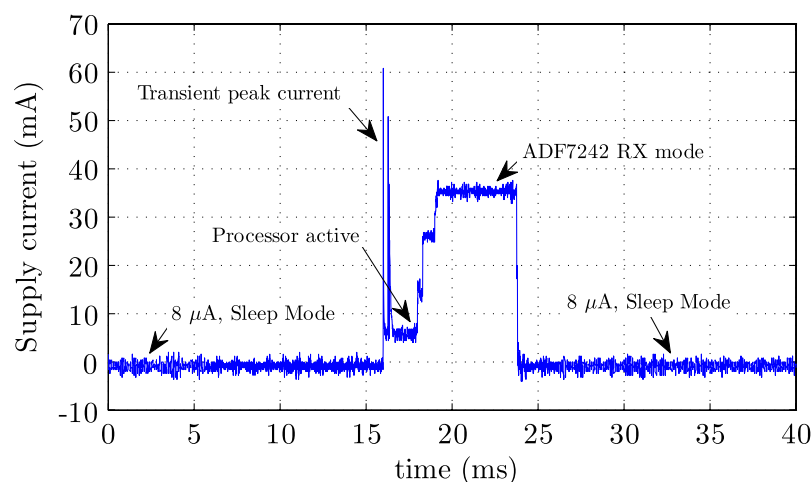

Fig. 14. Current consumption during RX mode (sleep current was measured by a Fluke 45 multimeter).

A number of practical values are listed in Table II. In addition, Table II depicts the system autonomy when complete absence of light is assumed and for two different battery types, being the integrated 170-mAh FLCB battery and a stateof-the-art 5-mm-thick 120-mAh lithium-ion coin cell battery (MULTICOMP LIR2450). In both the cases, the battery's leakage current is taken into account, being $40 \mu \mathrm{A}$ for the FLCB and $11 \mu \mathrm{A}$ for the coin cell. Note that the coin cell's smaller leakage current yields a higher system autonomy at higher values for the sleep time. Yet, the FLCB is preferred in our design because of its mechanical flexibility and its thinner profile. A protocol waking up the system every $10 \mathrm{~s}$ consumes an average supply current of $26 \mu \mathrm{A}$, guaranteeing a high system autonomy. In this mode, the system is standing by for interrogation and will answer within a maximum of $10 \mathrm{~s}$. Of course, the interrogating device should rapidly transmit subsequent packets in order to be sure that the node is able to effectively receive a packet during its active RX state of $5 \mathrm{~ms}$ duration. If the received packet contains the node's serial number, the node will immediately respond by transmitting a reply packet.

We prefer to use a protocol where the sleep period is automatically adjusted when interrogation of other nodes is detected. Receiving a packet intended for interrogation of another node indeed means a higher probability of interrogation in the near future, in which case it is interesting to temporarily reduce the sleep time to $1 \mathrm{~s}$, in order to allow faster subsequent interrogation of multiple nodes.

Fig. 15 shows the current consumption during the interrogation of the node. First, the node wakes up from sleep mode, and switches to RX mode, similar to the event shown

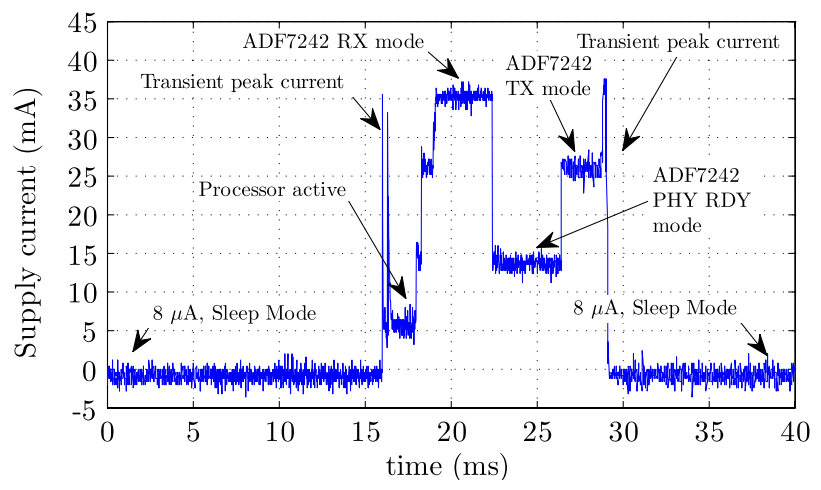

Fig. 15. Current consumption when the node is interrogated (sleep current was measured by a Fluke 45 multimeter).

in Fig. 14. However, a packet containing the node's serial number is now received, indicating proper interrogation. After the packet is received, the node returns from RX mode, performing further processing and SPI communication between the processor and the transceiver, requiring $12 \mathrm{~mA}$ of current. Finally, the node responds by transmitting a packet containing sensor data, consuming $27 \mathrm{~mA}$.

\section{CONClusion}

We have discussed the design, realization, and validation of a wearable, light-energy-harvesting-assisted sensing, processing, and decision-taking RFID tag for operation in the 2.45-GHz RFID SHF band. To the best of our knowledge, this is the first tag in the literature that combines excellent wearability with enhanced functionality, very high read range, and extended system autonomy, through a newly introduced holistic microwave system design paradigm, in which antenna design is taken into account from the early beginning. In addition, the tag features flexible interfacing with a wide variety of digital and analog low power sensors, such as accelerometers, light sensors, gas sensors, and temperature sensors. This enables us to adapt our design to a plethora of real-life applications by introducing the appropriate sensor(s). Furthermore, the enhanced RFID node is capable of taking decisions, through the processing of logged or realtime sensor data, even in the absence of an RFID reader. However, the increased functionality and read range come at an increased cost and power consumption of the RFID node compared with passive RFID tags, exclusively powered by an RFID reader. Yet, in our design, dedicated embedded software minimizes energy consumption, while system autonomy is further increased by the integration of a flexible MPPT lightenergy harvester. In addition, the higher cost of an individual RFID node does not necessarily lead to a higher cost of the overall system, as the excellent read range of our proposed RFID tag reduces the amount of RFID readers that are needed to cover a specific area. Hence, our design is a step forward in realizing the IoT paradigm. It is particularly suited for unobtrusive integration within a garment, leveraging pervasive quantification of the wearer's interaction with its environment, by wirelessly communicating physical information about the wearer and his/her nearby environment to the Internet via a question-and-reply protocol. 


\section{ACKNOWLEDGMENT}

The authors would like to thank Dr. Khelifi from the Solar Cells Lab, Department of Electronics and Information Systems (ELIS), Ghent University, for her valuable help with the PV module measurements, and Dr. Vanveerdeghem for his support in FCB assembly.

\section{REFERENCES}

[1] J. Gubbi, R. Buyya, S. Marusic, and M. Palaniswami, "Internet of Things (IoT): A vision, architectural elements, and future directions," Future Generat. Comput. Syst., vol. 29, no. 7, pp. 1645-1660, Sep. 2013.

[2] S. Amendola, R. Lodato, S. Manzari, C. Occhiuzzi, and G. Marrocco, "RFID technology for IoT-based personal healthcare in smart spaces," IEEE Internet Things J., vol. 1, no. 2, pp. 144-152, Apr. 2014.

[3] E. Welbourne et al., "Building the Internet of Things using RFID: The RFID ecosystem experience," IEEE Internet Comput., vol. 13, no. 3, pp. 48-55, May/Jun. 2009.

[4] M. T. Lazarescu, "Design of a WSN platform for long-term environmental monitoring for IoT applications," IEEE J. Emerg. Sel. Topics Circuits Syst., vol. 3, no. 1, pp. 45-54, Mar. 2013.

[5] Q. Chi, H. Yan, C. Zhang, Z. Pang, and L. Da Xu, "A reconfigurable smart sensor interface for industrial WSN in IoT environment," IEEE Trans. Ind. Informat., vol. 10, no. 2, pp. 1417-1425, May 2014.

[6] A. Costanzo and D. Masotti, "Wirelessly powering: An enabling technology for zero-power sensors, IoT and D2D communication," in Proc. IEEE MTT-S Int. Microw. Symp. (IMS), Phoenix, AZ, USA, May 2015, pp. $1-4$.

[7] N. B. Carvalho et al., "Wireless power transmission: R\&D activities within Europe," IEEE Trans. Microw. Theory Techn., vol. 62, no. 4, pp. 1031-1045, Apr. 2014.

[8] H. Sundmaeker, P. Guillemin, P. Friess, and S. Woelfflé, Eds., Vision and Challenges for Realising the Internet of Things. Brussels, Luxembourg: Pub. Office Eur. Union, 2010.

[9] S. Lemey, F. Declercq, and H. Rogier, "Textile antennas as hybrid energy-harvesting platforms," Proc. IEEE, vol. 102, no. 11, pp. 1833-1857, Nov. 2014.

[10] A. Dierck et al., "Active textile antennas in professional garments for sensing, localisation and communication," Int. J. Microw. Wireless Technol., vol. 6, nos. 3-4, pp. 331-341, Jun. 2014.

[11] V. Chaudhari, "Wearable electronics and technology market by applications (consumer, healthcare, enterprise), products (eyewear, wristwear, footwear), form factors and geography-Analysis \& forecast to 2014 2020," Markets and Markets, Magarpatta, India, Tech. Rep. SE 2763 Sep. 2014.

[12] S. Agneessens et al., "Design of a wearable, low-cost, through-wall Doppler radar system," Int. J Antennas Propag., vol. 2012, pp. 1-9, Jun. 2012

[13] L. Vallozzi, P. Van Torre, C. Hertleer, H. Rogier, M. Moeneclaey, and J. Verhaevert, "Wireless communication for firefighters using dualpolarized textile antennas integrated in their garment," IEEE Trans. Antennas Propag., vol. 58, no. 4, pp. 1357-1368, Apr. 2010.

[14] P. Van Torre, L. Vallozzi, C. Hertleer, H. Rogier, M. Moeneclaey, and J. Verhaevert, "Indoor off-body wireless MIMO communication with dual polarized textile antennas," IEEE Trans. Antennas Propag., vol. 59, no. 2, pp. 631-642, Feb. 2011.

[15] S. Agneessens, P. Van Torre, E. Tanghe, G. Vermeeren, W. Joseph, and H. Rogier, "On-body wearable repeater as a data link relay for in-body wireless implants," IEEE Antennas Wireless Propag. Lett. vol. 11, pp. 1714-1717, Jan. 2012.

[16] S. Park and S. Jayaraman, "Smart textile-based wearable biomedical systems: A transition plan for research to reality," IEEE Trans. Inf. Technol. Biomed., vol. 14, no. 1, pp. 86-92, Jan. 2010.

[17] G. Orecchini, M. M. Tentzeris, L. Yang, and L. Roselli, “'Smart Shoe': An autonomous inkjet-printed RFID system scavenging walking energy," in Proc. IEEE Int. Symp. Antennas Propag. (APSURSI), Spokane, WA, USA, Jul. 2011, pp. 1417-1420.

[18] L. Roselli, F. Alimenti, G. Orecchini, C. Mariotti, P. Mezzanotte, and M. Virili, "WPT, RFID and energy harvesting: Concurrent technologies for the future networked society," in Proc. Asia-Pacific Microw. Conf. (APMC), Seoul, South Korea, Nov. 2013, pp. 462-464.

[19] L. Roselli et al., "Smart surfaces: Large area electronics systems for Internet of Things enabled by energy harvesting," Proc. IEEE, vol. 102, no. 11 , pp. 1723-1746, Nov. 2014.
[20] M. Bozzi and R. Moro, "Low-cost fabrication, eco-friendly materials, and easy integration: The new technological paradigm for the future wireless sensor networks," in Proc. Eur. Microw. Conf. (EuMC), Nuremberg, Germany, Oct. 2013, pp. 858-861.

[21] S. Kim et al., "No battery required: Perpetual RFID-enabled wireless sensors for cognitive intelligence applications," IEEE Microw. Mag., vol. 14, no. 5, pp. 66-77, Jul. 2013.

[22] S. Kim et al., "Ambient RF energy-harvesting technologies for selfsustainable standalone wireless sensor platforms," Proc. IEEE, vol. 102, no. 11, pp. 1649-1666, Nov. 2014.

[23] A. P. Sample, J. Braun, A. Parks, and J. R. Smith, "Photovoltaic enhanced UHF RFID tag antennas for dual purpose energy harvesting," in Proc. IEEE Int. Conf. RFID, Orlando, FL, USA, Apr. 2011, pp. 146-153.

[24] H. Liu, M. Bolic, A. Nayak, and I. Stojmenovic, "Taxonomy and challenges of the integration of RFID and wireless sensor networks," IEEE Netw., vol. 22, no. 6, pp. 26-35, Nov. 2008.

[25] D. de Donno, L. Catarinucci, and L. Tarricone, "RAMSES: RFID augmented module for smart environmental sensing," IEEE Trans. Instrum. Meas., vol. 63, no. 7, pp. 1701-1708, Jul. 2014.

[26] R. Colella, L. Tarricone, and L. Catarinucci, "SPARTACUS: Selfpowered augmented RFID tag for autonomous computing and ubiquitous sensing," IEEE Trans. Antennas Propag., vol. 63, no. 5, pp. 2272-2281, May 2015.

[27] D. de Donno, L. Catarinucci, and L. Tarricone, "A battery-assisted sensor-enhanced RFID tag enabling heterogeneous wireless sensor networks," IEEE Sensors J., vol. 14, no. 4, pp. 1048-1055, Apr. 2014.

[28] T. Kaufmann, D. C. Ranasinghe, M. Zhou, and C. Fumeaux, "Wearable quarter-wave folded microstrip antenna for passive UHF RFID applications," Int. J. Antennas Propag., vol. 2013, pp. 1-11, May 2013.

[29] A. Hande, R. Bridgelall, and B. Zoghi, "Vibration energy harvesting for disaster asset monitoring using active RFID tags," Proc. IEEE, vol. 98, no. 9, pp. 1620-1628, Sep. 2010.

[30] T.-H. Tsai, B.-Y. Shiu, and B.-H. Song, "A self-sustaining integrated CMOS regulator for solar and HF RFID energy harvesting systems,' IEEE J. Emerg. Sel. Topics Power Electron., vol. 2, no. 3, pp. 434-442, Sep. 2014

[31] S. Lemey and H. Rogier, "SIW textile antennas as a novel technology for UWB RFID tags," in Proc. IEEE RFID Technol. Appl. Conf. (RFID-TA), Tampere, Finland, Sep. 2014, pp. 256-260.

[32] S. Agneessens, S. Lemey, T. Vervust, and H. Rogier, "Wearable, small, and robust: The circular quarter-mode textile antenna," IEEE Antennas Wireless Propag. Lett., vol. 14, pp. 1482-1485, Jan. 2015.

[33] O. Caytan et al., "Half-mode substrate-integrated-waveguide cavitybacked slot antenna on cork substrate," IEEE Antennas Wireless Propag. Lett., vol. 15, pp. 162-165, May 2015.

[34] M. Hasani, A. Vena, L. Sydänheimo, L. Ukkonen, and M. M. Tentzeris, "Implementation of a dual-interrogation-mode embroidered RFIDenabled strain sensor," IEEE Antennas Wireless Propag. Lett., vol. 12, pp. 1272-1275, Sep. 2013.

[35] M. Hasani, A. Vena, L. Sydanheimo, M. M. Tentzeris, and L. Ukkonen, "A novel enhanced-performance flexible RFID-enabled embroidered wireless integrated module for sensing applications," IEEE Trans. Compon., Packag., Manuf. Technol., vol. 5, no. 9, pp. 1244-1252, Sep. 2015

[36] S. Lemey and H. Rogier, "Substrate integrated waveguide textile antennas as energy harvesting platforms," in Proc. Int. Workshop Antenna Technol. (iWAT), Seoul, South Korea, Mar. 2015, pp. 23-26.

[37] S. Lemey, S. Agneessens, and H. Rogier, "Textile SIW antennas as hybrid energy harvesting and power management platforms,' in Proc. Eur. Microw. Conf. (EuMC), Paris, France, Sep. 2015, pp. 20-23.

[38] F. Declercq, A. Georgiadis, and H. Rogier, "Wearable aperture-coupled shorted solar patch antenna for remote tracking and monitoring applications," in Proc. 5th Eur. Conf. Antennas Propag. (EUCAP), Rome, Italy, Apr. 2011, pp. 2992-2996.

[39] A. Georgiadis and A. Collado, "Improving range of passive RFID tags utilizing energy harvesting and high efficiency class-E oscillators," in Proc. 6th Eur. Conf. Antennas Propag. (EUCAP), Prague, Czech Republic, Mar. 2012, pp. 3455-3458.

[40] J. Tak, S. Lee, and J. Choi, "All-textile higher order mode circular patch antenna for on-body to on-body communications," IET Microw., Antennas Propag., vol. 9, no. 6, pp. 576-584, Apr. 2015. 
[41] S. Lemey, F. Declercq, and H. Rogier, "Dual-band substrate integrated waveguide textile antenna with integrated solar harvester," IEEE Antennas Wireless Propag. Lett., vol. 13, pp. 269-272, Jan. 2014.

[42] IEEE Standard for Local and Metropolitan Area Networks 802.15.4-2011, IEEE Standard 802.15.4-2006, Sep. 2011.

[43] P. Vanveerdeghem, P. Van Torre, C. Stevens, J. Knockaert, and H. Rogier, "Flexible dual-diversity wearable wireless node integrated on a dualpolarised textile patch antenna," IET Sci., Meas. Technol., vol. 8, no. 6, pp. 452-458, Nov. 2014.

[44] A. Collado and A. Georgiadis, "Conformal hybrid solar and electromagnetic (EM) energy harvesting rectenna," IEEE Trans. Circuits Syst. I, Reg. Papers, vol. 60, no. 8, pp. 2225-2234, Aug. 2013.

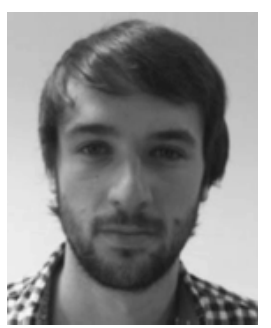

Sam Lemey (GSM'14) was born in 1990 $\mathrm{He}$ received the M.Sc. degree in electronics engineering from Ghent University, Campus Kortrijk, Belgium, in 2012. He is currently pursuing the $\mathrm{Ph} . \mathrm{D}$. degree in electrical engineering with the Electromagnetic Group, Department of Information Technology, and the Department of Electronics and Information Systems, Ghent University, Ghent, Belgium.

His current research interests include the design of textile antennas for smart fabric interactive textile systems, the reuse of textile antennas as hybrid energy harvesting and power management platforms, new techniques for implementing substrate integrated waveguide structures in textile materials, and ultrashort-range multiple-input multiple-output wireless communication.

Dr. Lemey was the recipient of the Best Paper Award at the 2016 IEEE MTT-S Topical Conference on Wireless Sensors and Sensor Networks.

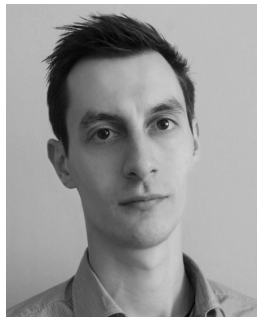

Sam Agneessens was born in Anderlecht, Belgium in 1986. He received the M.Sc. and Ph.D. degrees in electrical engineering from Ghent University, Ghent, Belgium, in 2011 and 2015, respectively.

He is currently a Post-Doctoral Fellow (FWO-V), and is affiliated with the Electromagnetic Group of the Department of Information Technology (INTEC) and the Centre for Microsystems (CMST) of the Department of Electronics and Information Systems (ELIS) at Ghent University. His research is focused on antennas for wearable applications, active antennas, and integrated mm-wave antennas for space applications and 5G systems.

Dr. Agneessens was the recipient of the URSI Young Scientist Award at the 2014 URSI General Assembly, the 2014 Premium Award for Best Paper in IET Electronics Letters, and an honorable mention in the Student Paper Competition at the 2014 IEEE International Symposium on Antennas and Propagation and the USNC-URSI Radio Science Meeting.

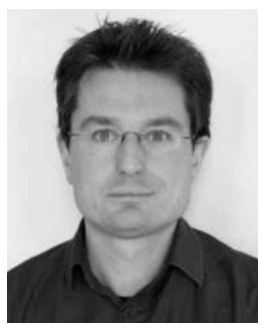

Patrick Van Torre received the M.Sc. degree in electrical engineering and Ph.D. degree in electrical engineering from Ghent University, Ghent, Belgium, in 1995 and 2012, respectively.

$\mathrm{He}$ is a Lecturer with the Faculty of Engineering and Architecture, Ghent University, where he teaches theory courses in electronics and ICT, organizes project-oriented lab sessions and public relations activities, as well as hardware and embedded software development projects. As a Researcher, he is active in the field of wireless communication, focusing on body-centric multiple-input multiple-output and beam-forming systems.
Kristof Baes, photograph and biography not available at the time of publication.

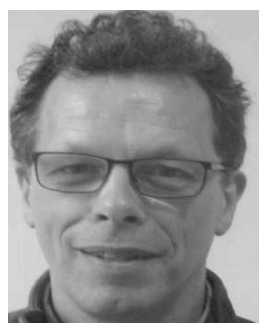

Jan Vanfleteren (M'00) received the Ph.D. degree in electronics engineering from Ghent University, Ghent, Belgium, in 1987.

$\mathrm{He}$ is currently a Principal Scientist with the IMEC-CMST Group and a part-time Professor with Ghent University. He has coauthored over 200 papers in international journals and conferences and holds 14 patents/patent applications. His current research interests include the development of novel interconnection, assembly, and substrate technologies, especially for wearable and implantable electronics and sensor applications.

Dr. Vanfleteren is a Member of IMAPS and MRS.

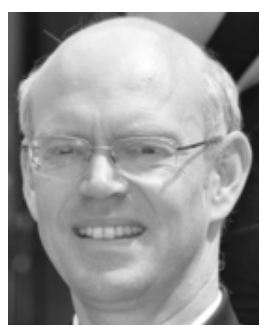

Hendrik Rogier (S'96-A'99-M'00-SM'06) was born in 1971. He received the M.Sc. and $\mathrm{Ph} . \mathrm{D}$. degrees in electrical engineering from Ghent University, Ghent, Belgium, in 1994 and 1999, respectively.

He was a Visiting Scientist with the Mobile Communications Group, Vienna University of Technology, Vienna, Austria, from 2003 to 2004. He is currently a Full Professor with the Department of Information Technology, Ghent University, a Guest Professor with iMinds, Ghent, Belgium, and a Visiting Professor with the University of Buckingham, Buckingham, U.K. He has authored or coauthored over 125 papers in international journals and more than 140 contributions in conference proceedings. His current research interests include antenna systems, radiowave propagation, body-centric communication, numerical electromagnetics, electromagnetic compatibility, and power/signal integrity.

Dr. Rogier was the recipient of the URSI Young Scientist Award twice at the 2001 URSI Symposium on Electromagnetic Theory and at the 2002 URSI General Assembly. In addition, he received the 2014 Premium Award for Best Paper in IET Electronics Letters, the Best Poster Paper Award at the 2012 IEEE Electrical Design of Advanced Packaging and Systems Symposium, the Best Paper Award at the 2013 IEEE Workshop on Signal and Power Integrity, the Joseph Morrissey Memorial Award for the first best scientific paper at BioEM 2013, and the 2016 IEEE MTT-S WiSNet Best Paper Award. He is serving as a Member of the Editorial Board of IET Science, Measurement Technology and Wireless Power Transfer. He acts as the URSI Commission B Representative for Belgium. Within the IEEE Microwave Theory and Techniques Society, he is a Member of the Technical Committee 24 on RFID Technology. Within the European Microwave Association, he is also a Member of the Governing Board of the Topical Group MAGEO on Microwaves in Agriculture, Environment, and Earth Observation. 